\title{
An X-Ray Microprobe Beam Line for Trace Element Analysis
}

\author{
BNL- -40759
}

DE88 006358

\author{
B. M. Gordon, A. L. Hanson, K. W. Jones, W. M. Kwiatek, \\ G. J. Long, J. G. Pounds, G. Schidlovsky, P. Spanne \\ Brookhaven National Laboratory, Upton, New York 11973
}

\author{
M. L. Rivers, S. R. Sutton \\ University of Chicago, Chicago, Illinois 60637
}

\section{DISCLAIMER}

This repore was prepared as an account of work sponsored by an agency of the United States Government. Neither the United States Government nor any agency thereof, nor any of their enployees, makes any warranty, express or implied, or assumes any legal liability or responsibility for the accuracy, completeness, or usefulness of any information, apparatus, product, or pricess disclosed, or represents that its use would not infringe privately owned rights. Reference herein to any specific commercial product, process, or service by trade name, trademark, manufacturer, or otherwise does not necessirily constitute or imply its endorsement, recommendation, or favoring by the United States Government or any agency thereof. The views and opinions of authors expressed herein do not necessarily state or reflect those of the United States Government or any agency thereof.

\section{Presented at}

The International Symposium on X-Ray Microscopy

Brookhaven National Laboratory, Upton, New York 11973

August 31-September 4, 1987

The submitted manuscript has been authored under Contract DE-ACO2-76CH00016 with the Office of Basic Energy Sciences, US Department of Energy. Accordingly, the US Government retains a nonexclusive, royalty-free license to publish or reproduce the published form of this contribution, or allow others to do so, for US Government purposes. 
An X-Ray Microprobe Beam Line for Trace Element Analysis

B. M. Gordon, A. L. Hanson, K. W. Jones, W. M. Kwiatek, G. J. Long,

J. G. Pounds, G. Schidlousky, P. Spanne

Brookhaven National Laboratory, Upton, New York 11973

M. L. Rivers, S. R. Sutton

Universtty of Chicago, Chtcago, Illinois 60637

\section{INTRODUCTION}

The application of synchrotron radiation to a $x$-ray microprobe for trace element analysis is a complementary and natural extension of existing microprobe techniques using electrons, protons, and heavier ions as excitation sources for $x$-ray fluorescence. This was first recognized by HOROWITZ and HOWELL [1] in their development of the first synchrotron radiation microprobe at the Cambridge Electron Accelerator. SPARKS, et a). [2] used a miniprobe beam at the Stanford Synchrotron Radiation Laboratory in an attempt to find natural occurring superheavy elements by $x$-ray fluorescence of characteristic L-lines. The ability to focus charged particles leads to electron microprobes with spatial resolutions in the sub-micrometer range and down to $100 \mathrm{ppm}$ detection limits and proton microprobes with micrometer resolution and ppm detection limits. The characteristics of synchrotron radiation that prove useful for microprobe analysis include a broad and continuous energy spectrum, a relatively smali amount of radiation damage compared to that deposited by charged particles, a highly polarized source which reduces background scattered radiation in an appropriate counting geometry, and a small vertical divergence angle of - $0.2 \mathrm{mrad}$ which allows for focussing of the light beam into a small spot with high flux. The features of a dedicated $x-r a y$ microprobe beam line developed at the National Synchrotron Light Source (NSLS) are described.

\section{EXPERIMENTAL}

In the first stage of development described here, the continuous spectrum was used with spot sizes produced by a set of remotely-controlled collimator slits. Appropriate absorbers were used to alter the excitation spectrum to maximize the sensitivity for a desired element or range of elements. The photon excitation beam, after traversing the collimator system, passes through a helium-filled ionization chamber for beam monitoring after which it falls on the target, held on a computer-controlled $X-y-Z-\theta$ translational stage with a $1-\mu m$ reproducibility. The target, held at $45^{\circ}$ to the beam, was observed by a $\mathrm{Si}(\mathrm{L} i)$ detector positioned at $90^{\circ}$ to the excitation beam in order to minimize the scattered radiation background. The target was continuously viewed by a microscope and video camera attachment. The slit system was capable of producing beams as small as $20 \times 20 \mathrm{\mu m}^{2}$. GIAUQUE, et al [3] used a Lawrence Berkeley Laboratory (LBL) designed synthetic multilayer focussing system to achieve a monochromated $10-\mathrm{keV}$ beam with 10-um resolution and 1-keV energy spread. 
The sensitivity for beam spot analyses in thin $\left(5 \mathrm{mg} / \mathrm{cm}^{2}\right)$ low 2 targets was approximately $0.5 \mathrm{ppm}$ for first row transition elements using an unfocussed continuous spectrum at $75 \mathrm{um}$ resolution in a 300-sec run. Using the LBL focussing system, a $10 \times 10 \mathrm{\mu m}^{2}$ beam spot using $10 \mathrm{keV}$ radtation yielded a range of $2 \mathrm{ppm}$ for $\mathrm{Cu}$ to $5 \mathrm{ppm}$ for $\mathrm{Mn}$ with the absolute detectable weight being in the 10- to 20 -fg range.

The present scanning technique uses a point microbeam and the target is scanned both vertically and horizontally across the beam. Regions on interest (ROI) are set up for each elemental $x$-ray fluorescence peak to be determined as shown in fig. 1 by the hatched areas. The integrated counts for each ROI, totally or with background subtracted, is determined on-line and recorded in the computer for off-line analysis. The spectrum is of a fetal rat bone explant after being cultured in a medium containing $25 \mu \mathrm{M}$ $\mathrm{Ga}\left(\mathrm{NO}_{3}\right)_{3}$. for a study in the use of gallium in cancer therapy. A 30-um section was made of the bone and an area of $1 \times 3 \mathrm{~mm}^{2}$ was scanned with 8 $40 \times 40 \mu^{2}$ pixel size and data collected at the rate of $2 \mathrm{sec} / \mathrm{pixel}$. The right side of the section contained the bony tissue whereas the left side was made up of cartilage. The results can be illustrated by threedimensional histograms, color contour pictures and, as illustrated in fig. 2, contour maps where the tick marks indicate the direction of lesser counts, i.e. downhill. The calcium, zinc, and gallium are seen to be held within the bony structure as well as most of the iron. The copper, whose origin is not known at present, resides principally on the surface of the cartilage. The highest integrated values for counts/pixel ranged from 15,000 for $\mathrm{Ca}, 5000$ for Ga to 400 for both $2 n$ and $\mathrm{Cu}$.

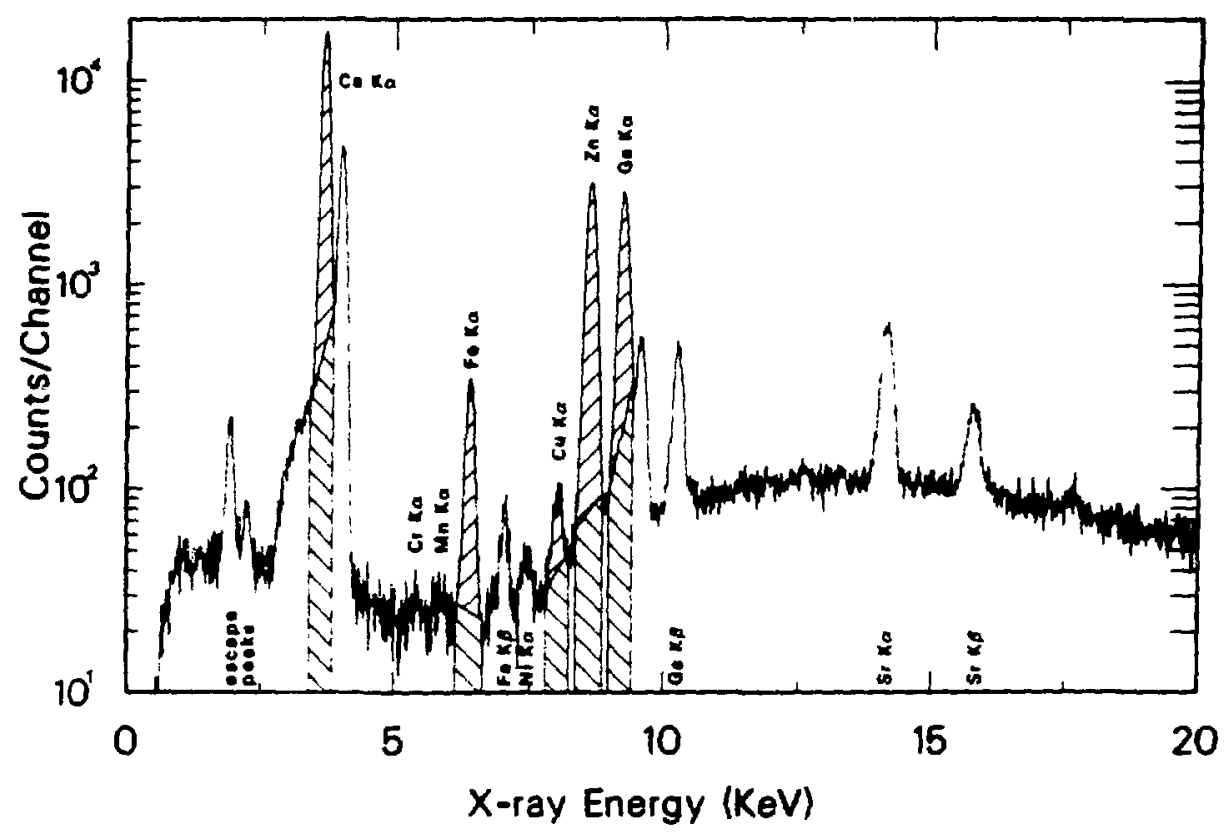

Fig. 1. X-ray fluorescence spectrum of fetal rat bone section after administration of gallium. The shaded areas are regions of interest for the elements being determined. 




Fig. 2. Contour plots for the distribution of counts/pixel for determined elements. Tick marks point in direction of lesser counts.

Other special applications of the $x$-ray microprobe beam line include the trace element analysis of living cells, made possible by the unique characteristics of synchrotron radiation enumerated above. A prototype wet cell was designed, constructed, and tested using cat cardiac myocytes, and major trace elements such as iron could be quantitated in single myocytes. Nutrient solution can be passed through the irradiation cell, which essentially is made up of two Kapton foils separated by a Kapton spacer foil with the perimeter of the cell cut out. Thusly, cells of about $10-\mu \mathrm{m}$ depth can be used.

Figure 3 illustrates a transmission tomogram of a freeze-dried caterpillar head with a 30-um pixel size. This example of microtomography was made in 50 min using both a translational and a rotational stage. In the future, mappings of trace elements will be made in cross section (depth) by detection of fluorescence $x$ rays with a point beam or in thin samples using a line source, as illustrated by KNOCHEL et al. [4] using the light source at DESY. 


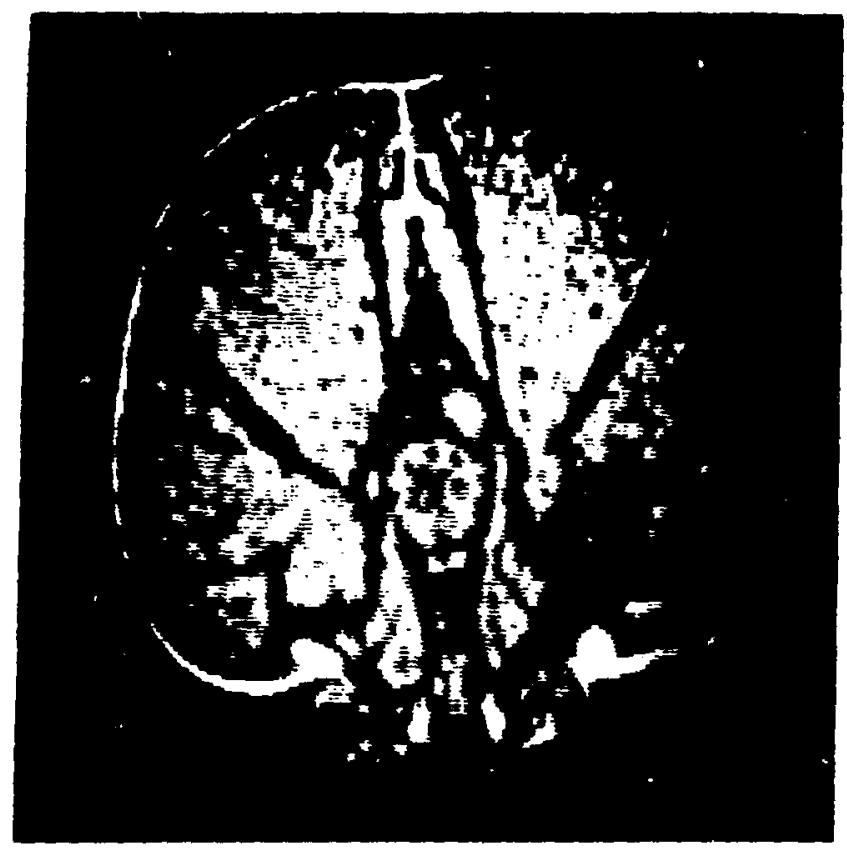

Fig. 3. Transmission tomograph of freeze-dried caterpillar head. The pixel size is $30 \times 30 \mu^{2}$ and the scan dimension is $177 \times 177$ pixels.

\section{ACKNOWLEDGMENTS}

Work supported in part by Processes and Techniques Branches, Division of Chemical Sciences, Office of Basic Energy Sciences, US Department of Energy, under Contract No. DE-ACO2-76CH00016: applications to biomedical problems by the National Institutes of Health as a Biotechnology Research Resource under Grant No. P41RR01838; applications in geochemistry by National Science Foundation Grant No. EAR-8618346; and applications in cosmochemistry by NASA Grant No. NAG 9-106.

\section{LITERATURE REFERENCES}

1. P. Horowitz and J. A. Howe 11: Science 178, 608 (1972)

2. C. J. Sparks, Jr., S. Raman, H. L. YakeT, R. V. Gentry, M. O. Krause: Phys. Rev. Lett. 38, 205 (1977)

3. R. O. Giauque, A. C. Thompson, J. H. Underwood, Y. Wu, K. W. Jones, M. L. Rivers: Anal. Chem., submitted

4. A. Knochel, M. Bavdaz, M. Gurker, P. Ketelsen, P. Petersen, M. H. Salehi, T. Dietrich: Proceedings of Symposium on Accuracy in Trace Analysis, National Bureau of Standards, Gaithersburg, Maryland, September 28,1987 , to be publ ished 